\title{
Forest fires and adaptation options in Europe
}

\author{
Nikolay Khabarov • Andrey Krasovskii • Michael Obersteiner • \\ Rob Swart · Alessandro Dosio · Jesús San-Miguel-Ayanz • \\ Tracy Durrant $\cdot$ Andrea Camia $\cdot$ Mirco Migliavacca
}

Received: 25 June 2013/Accepted: 12 April 2014/Published online: 7 September 2014

(C) The Author(s) 2014. This article is published with open access at Springerlink.com

\begin{abstract}
This paper presents a quantitative assessment of adaptation options in the context of forest fires in Europe under projected climate change. A standalone fire model (SFM) based on a state-of-the-art large-scale forest fire modelling algorithm is used to explore fuel removal through prescribed burnings and improved fire suppression as adaptation options. The climate change projections are provided by three climate models reflecting the SRES A2 scenario. The SFM's modelled burned areas for selected test countries in Europe show satisfying agreement with observed data coming from two different sources (European Forest Fire Information System and Global Fire Emissions Database). Our estimation of the potential increase in burned areas in Europe under "no adaptation" scenario is about $200 \%$ by 2090 (compared with 2000-2008). The application of prescribed burnings has the potential to keep that increase below $50 \%$. Improvements in fire suppression might reduce this impact even further, e.g. boosting the probability of putting out a fire within a
\end{abstract}

N. Khabarov $(\bowtie) \cdot$ A. Krasovskii $\cdot$ M. Obersteiner International Institute for Applied Systems Analysis, Schlossplatz 1, 2361 Laxenburg, Austria

e-mail: khabarov@iiasa.ac.at

R. Swart

Alterra, Wageningen University and Research Centre, Droevendaalsesteeg 3a, Building 100, 6708 PB Wageningen, The Netherlands

A. Dosio · J. San-Miguel-Ayanz · T. Durrant · A. Camia Institute for Environment and Sustainability, European Commission - Joint Research Centre, Via Fermi 2749, 21027 Ispra, Italy

M. Migliavacca

Max Planck Institute for Biogeochemistry, Hans-Knöll-Str. 10, 07745 Jena, Germany day by $10 \%$ would result in about a $30 \%$ decrease in annual burned areas. By taking more adaptation options into consideration, such as using agricultural fields as fire breaks, behavioural changes, and long-term options, burned areas can be potentially reduced further than projected in our analysis.

Keywords Forest fires - Europe - Adaptation · Climate change

\section{Introduction and background}

Adaptation to climate change becomes increasingly important for the scientific community and decision-makers. With respect to forest fires, the impacts of warmer and drier weather observed in the past are expected to become stronger in the future under projected climate change (Pechony and Shindell 2010; Rego et al. 2010; Schelhaas et al. 2010; San-Miguel-Ayanz et al. 2013b). Fires are one of the main disturbances that affect terrestrial ecosystems and have profound consequences on global climate, air quality, and vegetation structure and functioning (Bowman et al. 2009; Marlier et al. 2012). In Europe alone, fires impact more than half a million hectares of forest every year. Although fire is required for the natural seeding of plant species in some (e.g. Mediterranean) ecosystems (Vélez 1990), the aggregate consequences of large-scale destruction are overwhelmingly negative: fires devastate the carbon storage of forests and can lead to large economic damages and loss of life (San-Miguel-Ayanz and Camia 2010).

Fire regimes are determined by climate, vegetation, and direct human influence. Climate is recognized as the major determinant of fire patterns on a global scale (Marlon et al. 
2008). In Europe, human activities including negligence and arson cause more than $95 \%$ of European forest fires (Ganteaume et al. 2012; San-Miguel-Ayanz et al. 2012). At the same time, overall trends are closely linked to weather conditions (Rogelj et al. 2012), and climatic, socio-economic, and landscape fire drivers should be considered together to better understand inter-annual variations in burned areas (Costa et al. 2010).

A substantial decrease in summer precipitation (up to $70 \%$ ) is projected for 2070-2099 in some areas of southern Europe, increasing the frequency and severity of forest fires (Alcamo et al. 2007). In the other parts of Europe, the fire risk is also likely to increase (Alcamo et al. 2007). Active forest and fire management practices can counteract the impacts of a changing climate to some extent. An analysis of the fire risk management options in European forestry at national level shows that an increase in harvest level can stop the current build-up of growing stock and possibly decrease forest vulnerability through the reduction in old and susceptible stands (Schelhaas et al. 2010). Changing species from conifers to broadleaves might be also a viable option in the long run (Schelhaas et al. 2010). Other analyses show that the creation of agricultural fields in marginal areas is one of the most promising strategies to mitigate the effects of climate change on fire regimes, as agricultural fields can act as fire breaks preventing the spread of fire and hence reducing burned area (Lloret et al. 2002; Loepfe et al. 2002). In Mediterranean areas, enhancement of fire-fighting capacities and lowering the fuel load are found to be promising adaptation strategies for reducing fire spread, ultimately leading to consistent reductions in burned areas (Lloret et al. 2002). Nevertheless, no realistic management strategy is found to offset totally the effect of climate change (Loepfe et al. 2012), and other assessments of fire management strategies suggest that suppression and prescribed fire policies can effect only a small reduction in the total burned area (Piñol et al. 2007). Even though fire prevention measures together with improvements in fire-fighting capacity can help fire management, there are no conclusive results on how they support the reduction in extreme fire events in the Mediterranean region (San-Miguel-Ayanz et al. 2013a)

The present study is designed to explore the impact of adaptation options with regard to forest fires in Europe under projected climate change reflecting the SRES A2 scenario (Nakicenovic and Swart 2000) of the Intergovernmental Panel on Climate Change (IPCC). The main aims of our study are: (1) to quantify the potential impacts of climate change on burned area in Europe under "no adaptation" scenario and compare the results with existing literature and (2) to extend that assessment with quantitative estimation of the potential effectiveness of different adaptation measures at pan-European scale. Among the different adaptation options, we test fuel removal via prescribed burnings and enhancement of fire suppression. These options were developed in consultation with relevant stakeholders, who provided essential inputs to the research.

\section{Methods}

Impact assessment

As a basis for modelling the potential impact of climate change on burned area in Europe, we employed a widely used terrestrial biosphere model Community Land Model (CLM) (Levis et al. 2004; Stöckli et al. 2008). The model uses a process-based fire parameterization algorithm that was specifically developed for dynamic global vegetation models (Arora and Boer 2005) and was later modified and integrated as a module within CLM (Kloster et al. 2010). Thusly augmented, CLM was used to estimate climate impact on fires on a global scale (Kloster et al. 2012), and later was refined and parameterized for the application over Europe evolving to the CLM-AB model (Migliavacca et al. 2013). CLM-AB includes both climatic and socio-economic drivers of forest fires, allowing for the implementation of adaptation strategies in the model code. This model was selected because it is able to capture the complex interactions among burned area, climate, and fuel variability in Europe (Migliavacca et al. 2013). One drawback of CLM-AB is a systematic overestimation of burned areas (Migliavacca et al. 2013), and a practical consideration is its significant computational resource requirements. For these reasons, we developed for this study a standalone fire model (subsequently: SFM). This version of the CLM-AB fire module is fully decoupled from CLM and is calibrated using a different approach.

\section{Modelling strategy}

Although the SFM model is derived from CLM-AB, it uses only datasets fully independent of CLM-AB (weather, biomass, population density) and makes its own fuel moisture computation from the ground up based on the Canadian fine fuel moisture code (FFMC) index (Van Wagner and Pickett 1985). In SFM, we also implemented a procedure for calibration of suppression efficiency which differs from CLM-AB.

Suppression efficiency depends on a number of factors, including local regulations and available resources, and varies from one country to another. In SFM as well as in CLM-AB fire module (Arora and Boer 2005), the efficiency of fire suppression is defined as the probability $q$ of putting out a fire on a given day. Potential area burned 
within 1 day and also cumulative burned area over any time period can be represented as

$A(q)=a(1-q)(2-q) / q^{2}$,

where the coefficient $a$ reflects availability of fuel, ignition sources, and weather conditions, but is not a function of $q$ (Arora and Boer 2005; Kloster et al. 2010). In our calibration procedure, we find a value of the variable $q=q_{\mathrm{c}}$ such that $A\left(q_{\mathrm{c}}\right)=A_{\mathrm{obs}}$, where $A_{\mathrm{obs}}$ is the observed cumulative burned area in a specific country over a given time period. Based on a non-calibrated model run with an arbitrary value of $q=q_{0}\left(0<q_{0}<1\right)$ delivering accumulated burned area $A\left(q_{0}\right)$ for a time period for a given country, the calibrated value $q_{\mathrm{c}}$ is defined by the following equation:

$q_{\mathrm{c}}=\frac{-3+\sqrt{8 \beta+1}}{2(\beta-1)}$,

where $\beta=\frac{A_{\text {obs }}}{A\left(q_{0}\right)}\left(1-q_{0}\right)\left(2-q_{0}\right) / q_{0}^{2}$.

The value of parameter $\beta$ apparently equals $A_{\mathrm{obs}} / a$, and therefore, the calibrated value of suppression efficiency $q_{\mathrm{c}}$ does not depend on the arbitrary selected value $q_{0}$. The calibration method defined in Eq. (2) is rather straightforward as it requires only information on observed cumulative burned area and one test run of a non-calibrated model. We apply the country-level calibration procedure described above forcing the model to fit the reported total accumulated burned area over a time period of several years, which is long enough relative to the model's operating daily time step. An even more advanced spatially explicit (pixel level) calibration of $q$ did not add any substantial improvements to the accuracy of modelling of country-level aggregated annual burned areas. The calibration procedure we suggested above allows for resolving the problem of modelled burned area systematically overestimating the observations reported for CLM-AB (Migliavacca et al. 2013). The approach used for calibration in CLM-AB (Migliavacca et al. 2013) is based on a different method employing the mean fire suppression time reported in the European Fire Database (EFDB) developed in the context of the European Forest Fire Information System (EFFIS) (San-MiguelAyanz et al. 2013b).

\section{Input data and set-up}

The SFM model uses the global dataset of meteorological forcing, subsequently referred to as the Princeton dataset ${ }^{1}$ (Sheffield et al. 2006), which has a spatial resolution of 1 arc degree, and for the time span of 1948-2008 provides historical daily values of temperature, precipitation, wind,

$\overline{1}$ http://hydrology.princeton.edu/data.pgf.php. specific humidity, and surface pressure. Relative humidity, which is needed for the moisture calculation implemented through FFMC (Van Wagner and Pickett 1985), was derived from temperature, specific humidity, and surface pressure by utilizing saturation vapour pressure approximation (Flatau et al. 1992).

With SFM, we investigated possible impacts of climate change and respective adaptation options based on projections provided by different Global Climate Models (GCMs) reflecting the SRES A2 scenario (Nakicenovic and Swart 2000) of the IPCC. We selected A2, a high emissions scenario, because it allows us to analyse relatively large projected climate changes. For the period 2090-2099, A2 falls between newer IPCC scenarios (Moss et al. 2010) RCP6 and RCP8.5 (Rogelj et al. 2012). For the sake of brevity, we present SRES A2 related results for three GCMs: MRI-CGCM2.3.2 (Meteorological Research Institute, Japan), CNRM-CM3 (Météo-France/Centre National de Recherches Météorologiques, France), and CSIROMk3.0 (CSIRO Atmospheric Research, Australia), all part of the World Climate Research Programme's (WCRP's) Coupled Model Intercomparison Project phase 3 (CMIP3) multi-model dataset (Meehl et al. 2007). We used historical daily data from the Princeton dataset to estimate in a simplified way future daily values based on changes in mean monthly temperature and mean monthly precipitation coming from GCMs for the three future periods 2026-2035, 2046-2055, and 2086-2095 and relative to the historical baseline 1961-1970 (Strzepek 2012a, b). Changes in mean monthly temperature are added to each day's value to estimate future daily temperatures. Relative changes in monthly precipitation are used to multiply historical values to project future daily precipitation. This simplified approach for modelling future daily weather has several limitations, including the same number of "wet" days per month as in the historical period, and unchanged values for wind speed and relative humidity.

We used the dead wood and litter carbon data from the Global Forest Biomass map (Kindermann et al. 2008) - a half degree global spatial dataset. The use of a static biomass data is one of the simplifications of the SFM's modelling approach; a dynamic modelling of biomass with reasonable accuracy could help to refine the results of this analysis. In SFM, we make another simplification with the exclusion of lightning as a non-anthropogenic source of ignition. This simplification is justified because ignition potential due to high population density entirely overrules non-anthropogenic causes in Europe, where only $5 \%$ of wildfires are sparked by lightning (Catry et al. 2010).

The SFM model is calibrated as described above over a nine-year period 2000-2008 using burned area statistics reported in EFFIS (San-Miguel-Ayanz et al. 2013b) and, as an alternative for comparison, the Global Fires Emissions 
Database (GFED) version 3 (Giglio et al. 2010; Van der Werf et al. 2010). These are different products in terms of spatial extent (regional vs. global), and methods for data acquisition, processing, and validation. As the population density dataset, we used GPW version 3 (CIESIN 2005).

\section{Adaptation strategies}

A number of options are available to reduce the fire risk associated with anticipated climate change. In addition to improvements in active fire suppression, there is also a range of preventive strategies such as prescribed burnings (Silva et al. 2010), management options aimed at restricting the potential spread of fire (e.g. utilizing agricultural fields as fire breaks) (Lloret et al. 2002), and long-term options that include increase in rotation length and change of tree species (Schelhaas et al. 2010). Various combinations of reactive and preventive measures can also be pursued to reduce risk, improve flexibility, and optimize the use of available resources.

This study is focused on a subset of available options, namely: active suppression and fuel removal by prescribed burnings. These specific adaptations are applicable on regional and continental scales and were identified in dialogue with the experts and stakeholders in the field of fire management and forest sector. ${ }^{2}$ The SFM model is designed to evaluate those adaptation options on a continental scale, quantifying their potential impact under selected climate change scenarios.

Prescribed burnings in SFM were simulated by explicitly reducing available fuel biomass as a consequence of planned preventive fires. Following the CLM-AB's fuel representation approach (Migliavacca et al. 2013), we defined fuel available for burning as a combination of litter and coarse woody debris (CWD) pools, excluding stem biomass and shrub and grass components. As an estimate of the degree of fuel reduction induced by prescribed burnings, we used the values of $50 \%$ for both litter and CWD pools as suggested for needle leaf trees (Kloster et al. 2010). Because the values for broadleaf trees are higher (60\%), our approach is rather conservative.

We model potential improvements in fire suppression through modification of the parameter $q$ (Eq. 1). There are certain limitations on the use of $q$ as a proxy for the suppression capacity, mainly resulting in difficulties in disentangling detection and response components, and other related factors; e.g. setting up fire breaks. As an implication, the current version of the fire module only allows for sensitivity analysis of the aggregated proxy variable

\footnotetext{
2 The consultations were hosted by the Expert Group on Forest Fires (EGFF) of the European Commission http://ec.europa.eu/transparency/ regexpert/index.cfm?do=groupDetail.groupDetail\&groupID=416.
}

$q$ rather than of more explicit indicators. Nevertheless, this approach provides a quantification of impacts of reactive and preventive adaptation strategies at a large scale within a single modelling framework.

Additional options for risk reduction are excluded from the analysis. The fire algorithm of CLM-AB (Arora and Boer 2005), designed for large-scale applications, is not able to catch such local details as agricultural fields serving as fire breaks. Similarly, transition to fire-resistant tree species cannot be handled adequately because the model employs a simplified representation of fuel which does not distinguish among species (and also does not explicitly account for shrub and grass fuel components). Behavioural aspects, though important, are difficult to capture in this type of model and are therefore also excluded.

\section{Results and discussion}

Yearly forest fire dynamics during the historical period

By construction, the SFM calibration procedure guarantees exact agreement between simulated and reported cumulative country-level burned areas over the entire historical nine-year period 2000-2008. However, the model describes reasonably well the inter-annual variability of burned areas.

Table 1 reports performance of the SFM model (GFED and EFFIS calibrated) in terms of burned area for seven countries: Italy, Portugal, Spain, France, Germany, Poland, and Sweden. We have selected these countries because their data reported in EFFIS cover the entire period 2000-2008. An evaluation of GFED with EFFIS data is also reported for comparison. Based on the annual values for the historical period 2000-2008, we report mean absolute error (MAE) in thousands of hectares and

Table 1 SFM performance in terms of modelled annual burned areas for the historical period 2000-2008 for selected countries

\begin{tabular}{|c|c|c|c|c|c|c|}
\hline \multirow[t]{2}{*}{ Country } & \multicolumn{2}{|c|}{$\begin{array}{l}\text { SFM versus } \\
\text { GFED }\end{array}$} & \multicolumn{2}{|c|}{$\begin{array}{l}\text { SFM versus } \\
\text { EFFIS }\end{array}$} & \multicolumn{2}{|c|}{$\begin{array}{l}\text { GFED versus } \\
\text { EFFIS }\end{array}$} \\
\hline & $r$ & MAE & $r$ & MAE & $r$ & MAE \\
\hline Italy & 0.664 & 26.90 & 0.677 & 29.20 & 0.644 & 34.70 \\
\hline Portugal & 0.716 & 108.00 & 0.790 & 80.00 & 0.944 & 29.70 \\
\hline Spain & 0.652 & 26.30 & 0.677 & 29.60 & 0.935 & 31.80 \\
\hline France & 0.565 & 5.35 & 0.753 & 11.40 & 0.639 & 15.40 \\
\hline Germany & -0.106 & 2.11 & 0.848 & 0.14 & 0.163 & 1.36 \\
\hline Poland & 0.398 & 2.45 & 0.703 & 4.61 & 0.341 & 6.04 \\
\hline Sweden & -0.006 & 1.49 & 0.256 & 1.51 & 0.004 & 2.08 \\
\hline
\end{tabular}

GFED and EFFIS data were used for model calibration and consecutive benchmarking. $r$ is the Pearson's correlation coefficient and MAE is the mean absolute error (in thousands of hectares) 
(a)

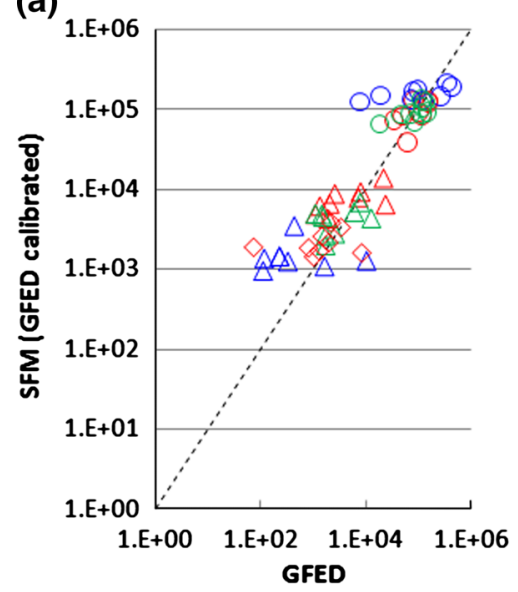

(b)

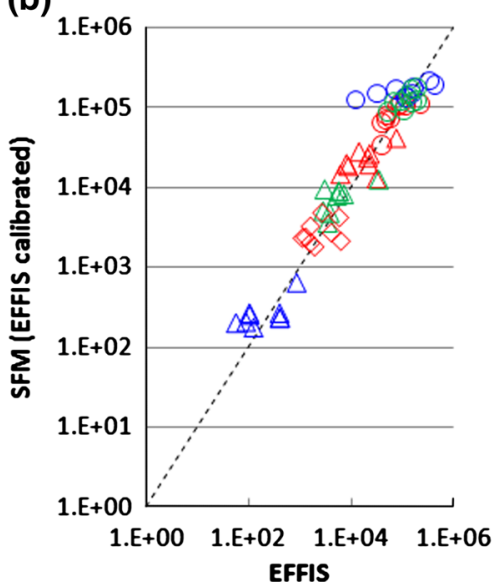

(c)

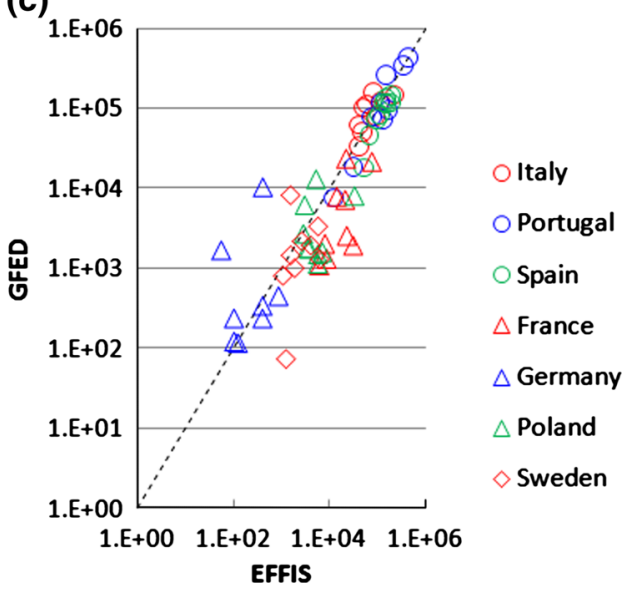

Fig. 1 Scatter plots of yearly burned areas (SFM modelled versus reported, and GFED versus EFFIS) in hectares on a log scale for selected countries

Pearson's correlation coefficient $r$. Generally, the agreement of the SFM model with EFFIS data is comparable or even better than the agreement of GFED with EFFIS. However, SFM notably has problems reproducing historical data for Portugal (see Fig. 1). A closer look at annual burned areas in Portugal uncovers the inability of the model to catch considerable peaks in 2003 and 2005. This is an instance of the general difficulty which mechanistic fire models suffer in simulating burned area for years with severe fire seasons. This limitation is due to incomplete description of fuel and weather interactions as well as an inadequate representation of the suppression probability of multiple simultaneous fires (Thonicke et al. 2001; Migliavacca et al. 2013). The variability of modelling accuracy across the selected test countries should be taken into account for future interpretation.

Figure 1 reports the scatter plot of observed (EFFIS and GFED) and modelled annual burned area. Both Fig. 1 and Table 1 show that SFM provides better agreement with EFFIS data than with GFED data. This might be due to the fact that GFED products suffer from omission errors when fires are of relatively small size (Kaiser et al. 2012).

The results of the comparison tests we performed show reasonable model performance as compared to GFED dataset in reproducing EFFIS data for a set of selected countries at a yearly time scale. In contrast to the EFFIS data, GFED provides spatially and temporarily consistent coverage at the European scale and is freely available. Therefore, we used GFED for final EU-wide model calibration and projections even though the agreement of the model is better with EFFIS for the analysed subset of EU countries. For projections into future periods, we do not utilize burned areas at the annual temporal resolution and estimate only 10-year averages for larger regions.
Regional impacts of adaptation strategies

In this section, we apply the adaptation strategies described above in "Adaptation strategies" to three European regions: Mediterranean (France, Greece, Italy, Portugal, Spain), the Balkan region and Eastern European countries (Croatia, Montenegro, Serbia, Slovenia, Slovakia, Hungary, Bulgaria, Macedonia, Czech Republic, Romania), and Central EU and Baltic countries (Austria, Germany, Belgium, The Netherland, Poland, Latvia, Lithuania, Estonia). In the analysis, we use $2000-2008$ as the reference period, and three future periods: 2026-2035, 2046-2055, and 2086-2095 for impact and adaptation assessments. We calculate average annual burned areas over these future 10 -year time intervals and report the results as average values for 2030, 2050, and 2090, respectively, while the average value for 2000 was calculated based on the historical period 2000-2008. The GFED-calibrated SFM model with climate projections coming from MRICGCM2.3.2, CNRM-CM3, and CSIRO-Mk3.0 GCMs is further referred to as $\mathrm{SFM}_{\mathrm{MRI}}, \mathrm{SFM}_{\mathrm{CNRM}}$, and $\mathrm{SFM}_{\mathrm{CSIRO}}$, respectively.

Projected impacts and the effect of fuel removal (prescribed burnings) as assessed by the SFM model for European regions are presented in Fig. 2. SFM $\mathrm{CNRM}_{\mathrm{C}}$ and $\mathrm{SFM}_{\mathrm{MRI}}$ deliver the greatest and the smallest impacts, respectively, for all three aggregated European regions, while the impact projection of $\mathrm{SFM}_{\mathrm{CSIRO}}$ falls between these estimations.

For the Mediterranean region (Fig. 2a), the yearly average burned area is projected to increase by approximately $150-220 \%$ in 2090 relative to 2000 . This result is in agreement with predictions of a $140 \%$ increase in burned areas for the time period 2070-2100 relative to 1985-2004, a figure obtained independently for the SRES 
(a)

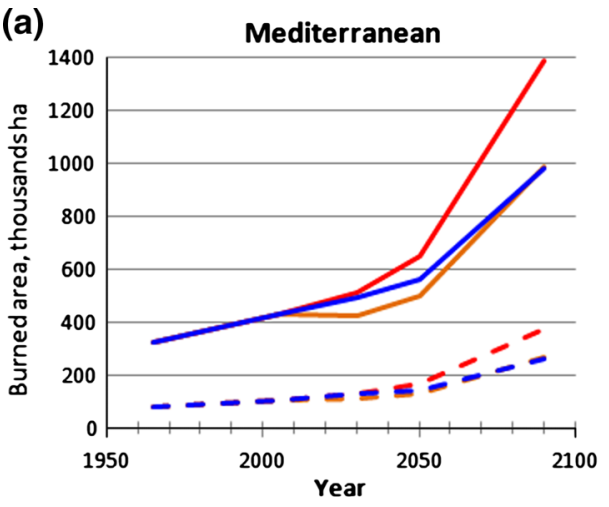

(c) Central EU and Baltic Countries

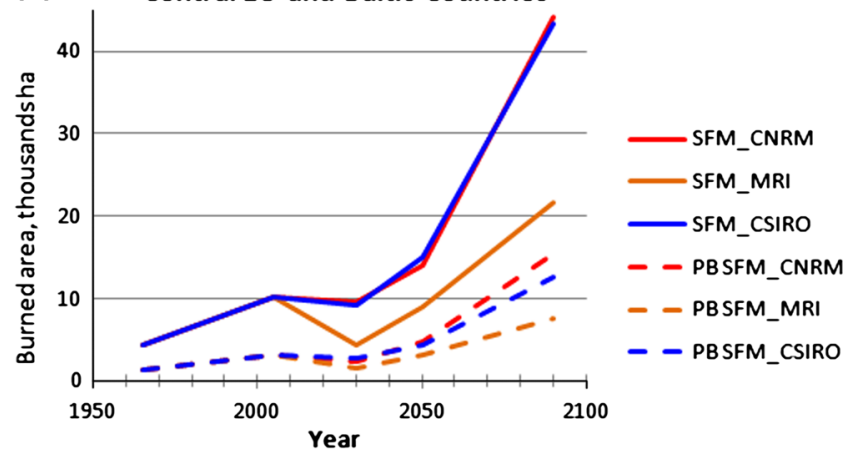

Fig. 2 Projected impacts and effect of fuel removal (prescribed burnings) on burned areas (in thousands of hectares) as assessed by $\mathrm{SFM}_{\mathrm{MRI}}, \mathrm{SFM}_{\mathrm{CNRM}}$, and $\mathrm{SFM}_{\mathrm{CSIRO}}$ models (all calibrated using

A2 scenario using a different (statistical) modelling approach (Amatulli et al. 2013). Relative to this baseline, prescribed burnings are projected to decrease the yearly burned areas on average by $74 \%$ in the Mediterranean by 2090. In the "no adaptation" scenario, the model predicts that the Balkan and Eastern European countries (Fig. 2b) will suffer an extreme 150-560\% increase in burned areas in 2090 relative to 2000 . In this region, prescribed burnings can potentially decrease the average yearly burned area in 2090 by about 47-69 \%. Results for Central EU and Baltic countries are shown in Fig. 2c, indicating an increase in burned areas by approximately $120-340 \%$ in 2090 over 2000. As in the other regions, the projected decrease in annual average burned areas due to prescribed burnings is about $70 \%$. In Fig. 2d, we show the results aggregated for the entire European region including 29 countries (all the regions analysed above in Fig. $2 \mathrm{a}-\mathrm{c}$ plus six additional countries: Switzerland, Finland, Sweden, Turkey, Norway, and UK. The projected impact of prescribed burnings in the entire European region does not substantially change over the considered future time slices $(2030,2050,2090)$ and, in 2090 , promises a $65-67 \%$ reduction in burned area relative to the "do nothing" scenario.

Our results draw out significant potential consequences of the SRES A2 climate change scenario in Europe. (b) Balcan and Eastern European Countries
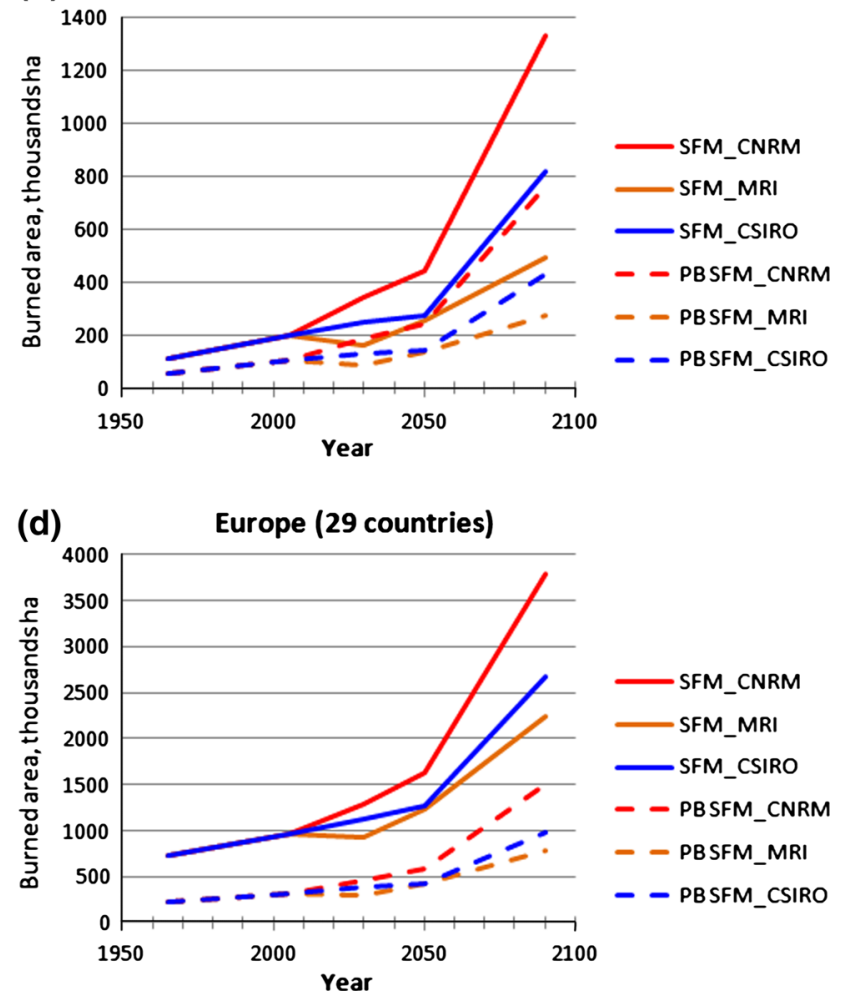

GFED) for European regions. Solid lines represent "no adaptation" scenario, dashed lines prescribed burnings (PB)

Studies on North America produce a similarly large impact assessment under SRES A2: burned areas in Alaska and western Canada are projected to increase by $250-450 \%$ by the last decade of the twenty-first century as compared to 1991-2000 (Balshi et al. 2009). The results of our study in terms of the estimated impact of prescribed burnings on burned areas, even though not always directly comparable, are in line with other studies on the effectiveness of prescribed burning for fire hazard reduction. For instance, a difference of about three times between the average size of a wildfire in treated and untreated areas in US has been shown (Fernandes and Botelho 2003). Similar results have also been obtained in Australia, where the average wildfire size was reported to be $50 \%$ smaller in treated areas.

For illustration purposes, we present the maps depicting the impact of prescribed burnings (fuel removal) in 2090s (Fig. 3). For this analysis, we apply spatially explicit (pixel level) calibration of $q$ mentioned in the "Modelling strategy" The SFM MRI model (GFED-calibrated on the historical period 2000-2008) estimates the average burned area in 2090s under the "no adaptation" and the "prescribed burnings" scenarios. The maps demonstrate that prescribed burnings may considerably decrease burned area in the European region in the future with the most 


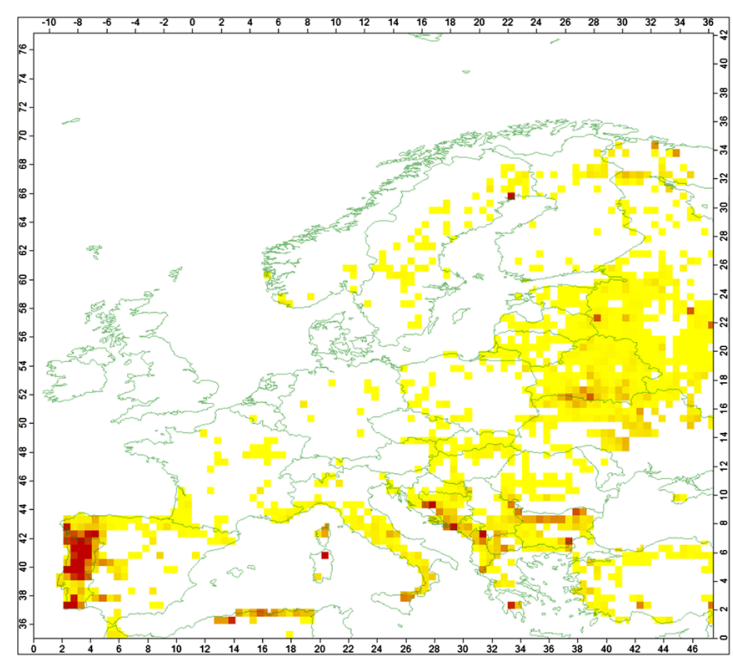

$\mathrm{SFM}_{\mathrm{MRI}} 2090 \mathrm{~s}$

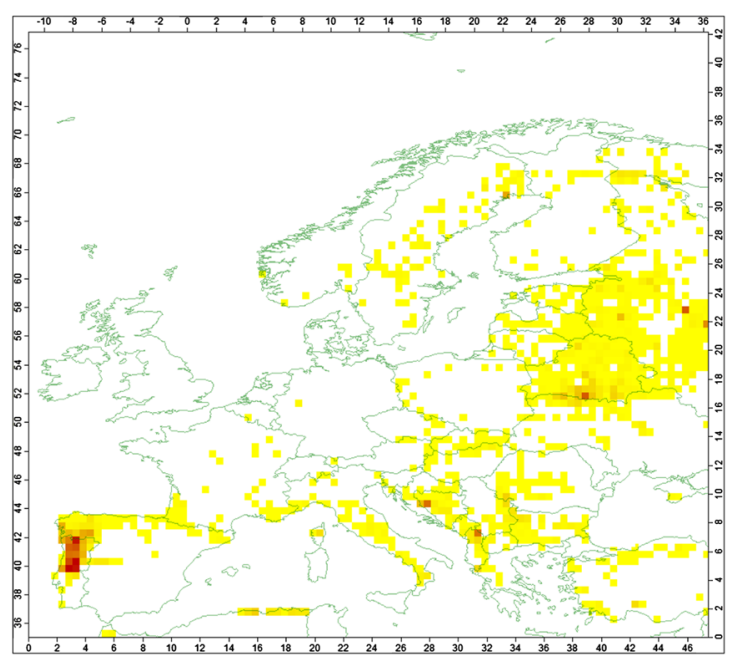

$\mathrm{SFM}_{\mathrm{MRI}} 2090$ s (with prescribed burnings)

Fig. 3 Spatially, explicit projection of yearly burned areas (hectares per a $25 \times 25 \mathrm{~km}$ pixel) estimated by SFM $\mathrm{MRI}_{\mathrm{model}}$ in $2090 \mathrm{~s}$ with and without prescribed burnings

prominent reduction visible in the Mediterranean as well as the Balkan and Eastern European regions.

We further analysed how changes in suppression strategies, described in terms of the parameter $q$, impacts the accumulated burned areas. We performed a sensitivity analysis on $q$ by varying this proxy to represent changes in each country's overall fire suppression abilities. A countryspecific burned area corresponding to a calibrated $q$ value is taken as unit value, and changes in burned areas with respect to $\pm 10 \%$ changes in $q$ are presented in Fig. 4 for the SFM model, calibrated using GFED data for years 2000-2008 for eight selected countries. In general, a relative change in $q$ of $\pm 10 \%$ leads to a relative change in burned areas of $\pm 30 \%$. The magnitude of this change depends nonlinearly on the initial value of $q$, with wider ranges observed for bigger values of $q$. An increase in $q$ can be interpreted as an improvement in active response to forest fires in a region and leads to a decrease in the burned area (Fig. 4).

In our modelling framework, fire suppression is not limited to a particular technique and potentially might include the use of fire itself, e.g. backfire, burning out, and counter firing (Silva et al. 2010). Even though preventive measures (fuel removal) were handled explicitly, the improved suppression was described only through a proxy variable aggregating detection, resource availability, and management. The existing modelling framework does not allow for separation of those different factors. Conclusions regarding the relative efficacy of investment in proactive and reactive measures cannot be rigorously undertaken in this framework for two reasons: first, due to the general nature of $q$ in contrast to specific definition of prescribed burnings; and second, because of the missing cost

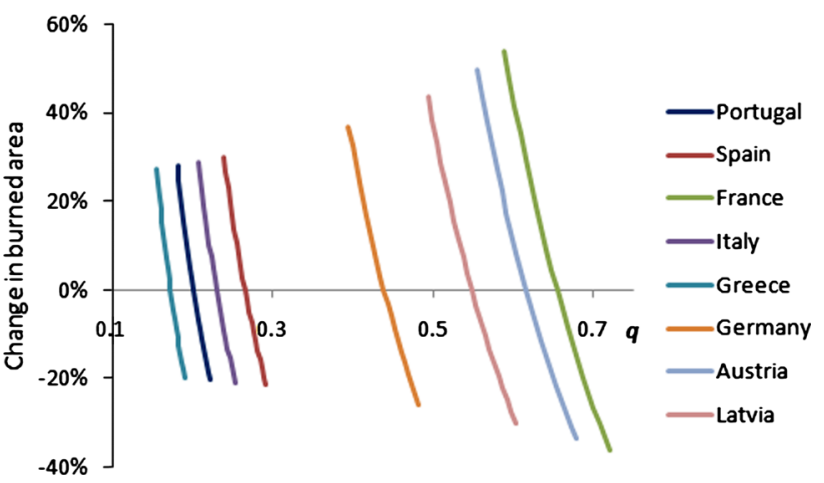

Fig. 4 Sensitivity analysis of suppression efficiency for the SFM model calibrated using GFED data for years 2000-2008. Changes in burned areas per country are in percents relative to burned area corresponding to calibrated value of $q$ (values of $q$ vary within $\pm 10 \%$ range)

component. Nevertheless, the presented framework allows for the assessment of a combined application of both modelled adaptation options because the model parameters relevant to prescribed burnings (fuel removal) and improved suppression are separable from each other, i.e. their respective burned area reduction factors multiply in the case of a combined application.

\section{Conclusions}

In this paper, we presented a framework for assessing the potential effectiveness of two adaptation options: (1) prevention through fuel reduction via prescribed burnings and (2) active response through better fire suppression. With 
the help of SFM, we carried out a model-based quantification of the potential effectiveness of prescribed burnings with respect to anticipated climate change under SRES A2 scenario on a pan-European scale.

The two options that we explored were discussed and selected in consultation with stakeholders, because, first, at a higher level of abstraction they represent two classes of approaches - prevention and reaction — and at the same time allow meaningful quantification and interpretation. Second, these options are potentially applicable at pan-European scale and, third, can be handled within the state-of-the-art large-scale fire models. Other relevant options, such as increasing land fragmentation and species conversion, cannot be properly modelled within the selected framework, because, first, the fire spread is estimated without taking into account the fragmentation of landscape, and second, because of a simplified representation of the fuel.

The simplified approach for modelling future daily weather that we have used for this study has several limitations, including the same number of "wet" days per month as in the historical period, and unchanged values for wind speed and relative humidity. Using a full set of future daily weather, variables generated by a "reliable" climate model would imply processing a much larger amount of data, but is definitely a way to go in the future to refine projections.

The quantitative results we obtained for model benchmarking on a historical period for selected countries show reasonable performance of the SFM model in terms of agreement of the modelled burned areas in Europe with observed data provided by EFFIS. However, the modelling accuracy still needs to be improved and the highlighted issues point to the directions for further development. As there are discrepancies between GFED and EFFIS data, the projections we obtained using GFED as a calibration dataset should be treated with caution. Our projections of climate change impact (without adaptation) and assessments of prescribed burnings efficiency (under present climate) are both derived as by-products for comparison purposes, and are in line with existing literature. However, there are no other studies providing quantitative estimates for direct comparison with our projections except for climate impact assessment on forest fires under SRES A2 scenario for Mediterranean countries (Amatulli et al. 2013). Our estimation of potential increase in annual burned areas in Europe under SRES A2 and "no adaptation" scenario is about $200 \%$ by 2090 , compared with 2000-2008. The application of prescribed burnings has a potential of keeping that increase below $50 \%$. Improvements in fire suppression might reduce this impact even further; e.g. boosting the probability of putting out a fire within a day by $10 \%$ country wide would result in about $30 \%$ decrease in annual burned area for that particular country. Since we did not include all potentially available adaptation options into our analysis, the effects of climate change can potentially be reduced beyond these indicative levels. Future efforts should be oriented at exploration of relevant costs and benefits that would ultimately define the feasible level of the impact reduction.

The need to overcome the current modelling limitations identified in the course of this research calls for a fundamental upgrade of the existing continental-scale fire models. This major step, however, is beyond the scope of the presented research and therefore is left for future elaborations.

Acknowledgments We thank Anatoly Shvidenko, Brian Walsh, Sandy Bisaro, Silvia Kloster, Christian Siderius, and Dan Ward for discussion, reviews, useful comments, and help. We also thank four anonymous reviewers who helped improving the manuscript. This research was undertaken as part of the MEDIATION project: Methodology for Effective Decision-making on Impacts and Adaptation. This project was funded by the European Commission, Seventh Framework Programme (FP7) under contract number 244012. The research has received funding from the EU's FP7 under grant agreements Nr. 226701 (CARBO-Extreme), Nr. 282746 (IMPACT2C), and Nr. 603906 (ECONADAPT). We acknowledge the modelling groups, the Program for Climate Model Diagnosis and Intercomparison (PCMDI) and the WCRP's Working Group on Coupled Modelling (WGCM) for their roles in making available the WCRP CMIP3 multi-model dataset. Support of this dataset is provided by the Office of Science, US Department of Energy. We thank Kenneth Marc Strzepek (strzepek@mit.edu) for processing the CMIP3 dataset and providing the projected mean monthly changes data.

Open Access This article is distributed under the terms of the Creative Commons Attribution License which permits any use, distribution, and reproduction in any medium, provided the original author(s) and the source are credited.

\section{References}

Alcamo J, Moreno J, Nováky B, Bindi M, Corobov R, Devoy R, Giannakopoulos C, Martin E, Olesen J, Shvidenko A (2007) Europe. Climate Change 2007: Impacts, Adaptation and Vulnerability. In: Parry M, Canziani O, Palutikof J, van der Linden P, Hanson C (eds) Contribution of Working Group II to the Fourth Assessment Report of the Intergovernmental Panel on Climate Change. Cambridge University Press, Cambridge, UK, pp 541-580

Amatulli G, Camia A, San-Miguel-Ayanz J (2013) Estimating future burned areas under changing climate in the EU-Mediterranean countries. Sci Total Environ 450-451:209-222. doi:10.1016/j. scitotenv.2013.02.014

Arora VK, Boer GJ (2005) Fire as an interactive component of dynamic vegetation models. J Geophys Res 110:G02008

Balshi MS, McGuire AD, Duffy P, Flannigan M, Walsh J, Melillo J (2009) Assessing the response of area burned to changing climate in western boreal North America using a Multivariate Adaptive Regression Splines (MARS) approach. Glob Change Biol 15:578-600. doi:10.1111/j.1365-2486.2008.01679.x

Bowman DMJS, Balch JK, Artaxo P, Bond WJ, Carlson JM, Cochrane MA, D'Antonio CM, DeFries RS, Doyle JC, Harrison SP, Johnston FH, Keeley JE, Krawchuk MA, Kull CA, Marston JB, Moritz MA, Prentice IC, Roos CI, Scott AC, Swetnam TW, van der Werf GR, Pyne SJ (2009) Fire in the Earth System. Science 324:481-484. doi:10.1126/science.1163886 
Catry F, Rego F, Silva J, Moreira F, Camia A, Ricotta C, Conedera M (2010) Fire starts and human activities. Towards integrated fire management: outcomes of the European project fire paradox. European Forest Institute, Joensuu pp 9-21

CIESIN (2005) Gridded Population of the World Version 3 (GPWv3): Population Density Grids. Center for International Earth Science Information Network (CIESIN), Columbia University; and Centro Internacional de Agricultura Tropical (CIAT), Socioeconomic Data and Applications Center (SEDAC), Columbia University, Palisades

Costa L, Thonicke K, Poulter B, Badeck F-W (2010) Sensitivity of Portuguese forest fires to climatic, human, and landscape variables: subnational differences between fire drivers in extreme fire years and decadal averages. Reg Environ Change 11:543-551. doi:10.1007/s10113-010-0169-6

Fernandes PM, Botelho HS (2003) A review of prescribed burning effectiveness in fire hazard reduction. International Journal of Wildland Fire 12:117. doi:10.1071/WF02042

Flatau PJ, Walko RL, Cotton WR (1992) Polynomial fits to saturation vapor pressure. J Appl Meteorol 31:1507-1513. doi:10.1175/ 1520-0450(1992)031\%3C1507:pftsvp\%3E2.0.co;2

Ganteaume A, Camia A, Jappiot M, San-Miguel-Ayanz J, LongFournel M, Lampin C (2012) A review of the main driving factors of forest fire ignition over Europe. Environ Manag 51(3):651-662

Giglio L, Randerson JT, van der Werf GR, Kasibhatla PS, Collatz GJ, Morton DC, DeFries RS (2010) Assessing variability and longterm trends in burned area by merging multiple satellite fire products. Biogeosciences 7:1171-1186. doi:10.5194/bg-7-11712010

Kaiser JW, Heil A, Andreae MO, Benedetti A, Chubarova N, Jones L, Morcrette JJ, Razinger M, Schultz MG, Suttie M (2012) Biomass burning emissions estimated with a global fire assimilation system based on observed fire radiative power. Biogeosciences 9:527-554

Kindermann GE, McCallum I, Fritz S, Obersteiner M (2008) A global forest growing stock, biomass and carbon map based on FAO statistics. Silva Fennica 42:387

Kloster S, Mahowald NM, Randerson JT, Thornton PE, Hoffman FM, Levis S, Lawrence PJ, Feddema JJ, Oleson KW, Lawrence DM (2010) Fire dynamics during the 20th century simulated by the community land model. Biogeosciences 7:1877-1902

Kloster S, Mahowald NM, Randerson JT, Lawrence PJ (2012) The impacts of climate, land use, and demography on fires during the 21st century simulated by CLM-CN. Biogeosciences 9:509-525. doi:10.5194/bg-9-509-2012

Levis S, Bonan GB, Vertenstein M, Oleson KW (2004) NCAR Technical note TN-459 + IA

Lloret F, Calvo E, Pons X, Díaz-Delgado R (2002) Wildfires and landscape patterns in the Eastern Iberian Peninsula. Landsc Ecol 17:745-759

Loepfe L, Martinez-Vilalta J, Piñol J (2012) Management alternatives to offset climate change effects on Mediterranean fire regimes in NE Spain. Clim Change 115:693-707. doi:10.1007/s10584-0120488-3

Marlier ME, DeFries RS, Voulgarakis A, Kinney PL, Randerson JT, Shindell DT, Chen Y, Faluvegi G (2012) El Niño and health risks from landscape fire emissions in southeast Asia. Nat Clim Change 3:131-136. doi:10.1038/nclimate1658

Marlon JR, Bartlein PJ, Carcaillet C, Gavin DG, Harrison SP, Higuera PE, Joos F, Power MJ, Prentice IC (2008) Climate and human influences on global biomass burning over the past two millennia. Nat Geosci 1:697-702. doi:10.1038/ngeo313

Meehl GA, Covey C, Taylor KE, Delworth T, Stouffer RJ, Latif M, McAvaney B, Mitchell JFB (2007) THE WCRP CMIP3 multimodel dataset: a new era in climate change research. Bull Am Meteorol Soc 88:1383-1394. doi:10.1175/BAMS-88-9-1383

Migliavacca M, Dosio A, Kloster S, Ward DS, Camia A, Houborg R, Houston Durrant T, Khabarov N, Krasovskii AA, San MiguelAyanz J, Cescatti A (2013) Modeling burned area in Europe with the community land model. J Geophys Res Biogeosci. 118(1):265-279. doi:10.1002/jgrg.20026

Moss RH, Edmonds JA, Hibbard KA, Manning MR, Rose SK, van Vuuren DP, Carter TR, Emori S, Kainuma M, Kram T, Meehl GA, Mitchell JFB, Nakicenovic N, Riahi K, Smith SJ, Stouffer RJ, Thomson AM, Weyant JP, Wilbanks TJ (2010) The next generation of scenarios for climate change research and assessment. Nature 463:747-756. doi:10.1038/nature08823

Nakicenovic N, Alcamo J, Davis G, de Vries B, Fenhann J, Gaffin S, Gregory K, Grübler A, Jung T, Kram T, La Rovere E, Michaelis L, Mori S, Morita T, Pepper W, Pitcher H, Price L, Riahi K, Roehrl A, Rogner H, Sankovski A, Schlesinger M, Shukla P, Smith S, Swart R, van Rooijen S, Victor N, Dadi Z (2000) Emissions Scenarios. In: Nakicenovic N, Swart R (eds) IPCC. Cambridge University Press, UK

Pechony O, Shindell DT (2010) Driving forces of global wildfires over the past millennium and the forthcoming century. Proc Natl Acad Sci 107:19167-19170

Piñol J, Castellnou M, Beven KJ (2007) Conditioning uncertainty in ecological models: assessing the impact of fire management strategies. Ecol Model 207:34-44. doi:10.1016/j.ecolmodel. 2007.03.020

Rego F, Rigolot E, Fernandes P, Montiel C, Silva JS (2010) Towards integrated fire management. European Forest Institute Policy Brief. Joensuu, Finland

Rogelj J, Meinshausen M, Knutti R (2012) Global warming under old and new scenarios using IPCC climate sensitivity range estimates. Nat Climate Change 2:248-253. doi:10.1038/ nclimate 1385

San-Miguel-Ayanz J, Camia A (2010) Forest Fires. In: Mapping the impacts of natural hazards and technological accidents in Europe an overview of the last decade. EEA Technical Report N13/ 2010. doi: $10.2800 / 62638$

San-Miguel-Ayanz J, Schulte E, Schmuck G, Camia A, Strobl P, Liberta G, Giovando C, Boca R, Sedano F, Kempeneers P, McInerney D, Withmore C, de Oliveira SS, Rodrigues M, Durrant T, Corti P, Oehler F, Vilar L, Amatulli G (2012) Comprehensive monitoring of wildfires in Europe: The European Forest Fire Information System (EFFIS). In: Approaches to managing disaster-assessing hazards, emergencies and disaster impacts. InTech. doi:10.5772/28441

San-Miguel-Ayanz J, Moreno JM, Camia A (2013a) Analysis of large fires in European Mediterranean landscapes: lessons learned and perspectives. For Ecol Manage 294:11-22. doi:10.1016/j.foreco. 2012.10.050

San-Miguel-Ayanz J, Schulte E, Schmuck G, Camia A (2013b) The European Forest Fire Information System in the context of environmental policies of the European Union. For Policy Econ 29:19-25. doi:10.1016/j.forpol.2011.08.012

Schelhaas M-J, Hengeveld G, Moriondo M, Reinds GJ, Kundzewicz ZW, Maat H, Bindi M (2010) Assessing risk and adaptation options to fires and windstorms in European forestry. Mitig Adapt Strat Glob Change 15:681-701. doi:10.1007/s11027-0109243-0

Sheffield J, Goteti G, Wood EF (2006) Development of a 50-year high-resolution global dataset of meteorological forcings for land surface modeling. J Clim 19:3088-3111

Silva JS, Rego F, Fernandes P, Rigolot E (2010) Towards integrated fire management: outcomes of the European project fire paradox. European Forest Institute, Joensuu 
Stöckli R, Rutishauser T, Dragoni D, O'Keefe J, Thornton PE, Jolly M, Lu L, Denning AS (2008) Remote sensing data assimilation for a prognostic phenology model. J Geophys Res. doi:10.1029/ 2008JG000781

Strzepek K (2012a) Indicators to understanding the impact of climate variability and change to flood risk. Technical report submitted to the Asian Development Bank. http://fws.iiasa.ac.at/docs/ Strzepek_ADB_Flood_Indicators.pdf. Accessed 23 May 2013

Strzepek K (2012b) A basin Scale indicator approach to understanding the risk of climate variability and change: to water resources development and management. Technical report submitted to the Asian Development Bank. http://fws.iiasa.ac.at/docs/Strzepek_ ADB_Indicator_Methodology.pdf. Accessed 23 May 2013

Thonicke K, Venevsky S, Sitch S, Cramer W (2001) The role of fire disturbance for global vegetation dynamics: coupling fire into a dynamic global vegetation model. Glob Ecol Biogeogr 10:661-677

Van der Werf GR, Randerson JT, Giglio L, Collatz GJ, Mu M, Kasibhatla PS, Morton DC, DeFries RS, Jin Y, van Leeuwen TT (2010) Global fire emissions and the contribution of deforestation, savanna, forest, agricultural, and peat fires (1997-2009). Atmos Chem Phys 10:11707-11735. doi:10.5194/acp-10-117072010

Van Wagner CE, Pickett TL (1985) Equations and FORTRAN program for the Canadian forest fire weather Index System. Canadian Forestry Service, Petawawa National Forestry Institute, Chalk River, Ontario

Vélez R (1990) Mediterranean forest fires: a regional perspective. Unasylva 41:3-9 